\title{
How do Chinese Agricultural Enterprises Carry on Open Innovation? Based on Entrepreneurial Social Capital
}

\author{
Jun Chen \\ School of Business and Tourism Administration \\ Yunnan University \\ Kunming, China \\ chenjun_ydkm@126.com
}

\author{
Qicheng Lu* \\ Business School \\ Yunnan University of Finance and Economics \\ Kunming, China \\ 317404322@qq.com
}

\begin{abstract}
In the process of technological innovation, Chinese agricultural enterprises face the dual predicament of external "knowledge market failure" and internal "knowledge management inefficiency". In this context, the open innovation paradigm has become an important choice for agricultural enterprises (especially the leading enterprises) to carry on their technological innovation. Based on the theory of social capital and open innovation, this paper analyzes the reasons for Chinese agricultural enterprises to adopt open innovation and the influence of the entrepreneurial social capital on the innovation activities of agricultural enterprises. Moreover, this paper sums up the impact mechanism of the social capital of agricultural entrepreneurs on knowledge acquisition, absorption and exploitation in the open innovation activities of their enterprises. On the basis of the traditional open innovation model, an open innovation model of Chinese agricultural enterprises based on the entrepreneur's social capital is built and some relevant propositions are put forward.
\end{abstract}

Keywords-agricultural enterprises; entrepreneurial social capital; open innovation; model

\section{INTRODUCTION}

Different from the industrialized agricultural enterprises in Europe and America, China's agricultural enterprises have the characteristics of small scale, short industrial chain, weak processing capacity and low technology of products and services [1], which directly lead to insufficient innovation output and weak innovation ability of enterprises. Some scholars have proposed that the open innovation model should be adopted to improve the innovation ability of agricultural enterprises in view of the special development pattern and characteristics of agricultural enterprises in China [2][3], and the special market environment of the emerging economies in the transition economy. But there is little research on how to carry out the open innovation of agricultural enterprises [4][5], and the practical problem is that it is difficult for agricultural enterprises to carry out open innovation. On the one hand, because intellectual property trading market is not mature in China, agricultural enterprises have "knowledge market failure", which is difficult to acquire the necessary knowledge resources effectively [7][8]. On the other hand, because most agricultural

*Corresponding author enterprises do not have the R \& $\mathrm{D}$ ability, there is internal "knowledge management inefficiency". The return from enterprises knowledge management is very limited [9][10], which makes it difficult for enterprises to be the beneficiaries of the knowledge diffusion to the market.

Therefore, how to do open innovation for agricultural enterprises is a new theme that needs to be studied urgently. Breaking through the external "knowledge market failure" and the internal "knowledge management inefficiency" in the enterprises, the entrepreneurs of some leading enterprises make good use of their rich entrepreneurial social capital to make up for the imbalance of knowledge allocation in the open innovation [11][12][13]14]. In the practice of open innovation, they have explored the open innovation road of the agricultural enterprise dominated by the entrepreneurial social capital.

How does entrepreneurial social capital affect open innovation in agricultural enterprises? This paper will introduce the theory of social capital, and build a model of entrepreneurial innovation based on entrepreneurial social capital and related propositions.

\section{OPEN INNOVATION OF AGRICULTURAL ENTERPRISES IN CHINA}

\section{A. Knowledge Flow in Open Innovation}

Since Chesbrough [15] proposed open innovation, the study of open innovation has been increasingly concerned by academia and industry. Open innovation assumes that useful knowledge is widely distributed, and even the most capable $\mathrm{R}$ \& D organizations need to identify, connect and exploit external knowledge as the core process of innovation [16]. So it is a process of distributed innovation, which relies on manageable knowledge flows across the organizational boundaries and uses money or non-monetary mechanisms in organizational business mode to guide and encourage knowledge sharing [17].

From the connotation of open innovation, it emphasizes a knowledge sharing mechanism across the organization boundary, and realizes the opening of the innovation process through the knowledge management process within the 
enterprise, thus promoting the creation of organizational innovation. Obviously, the connotation of open innovation does not set the enterprise characteristics as the prerequisite for the application of open innovation model. As long as it is open to the innovation process, the enterprises that make full use of the internal and external knowledge of enterprises to carry out organizational innovation are applicable.

In addition, open innovation is a kind of externalization of $\mathrm{R} \& \mathrm{D}$ activities caused by the external environment, and it is also a kind of behavior of $\mathrm{R} \& \mathrm{D}$ externalization resulting from the barriers and deficiencies of internal innovation in the enterprise, and it is the behavior of the entrepreneur 's active choice [18]. In other words, the choice of an open innovation model of an enterprise does not depend on the characteristics of the enterprise itself, but depends on the internal and external environment of the enterprise and the choice of the entrepreneur.

The knowledge process of the open innovation in the enterprise includes three core processes, inbound, outbound and coupling process. Not every enterprise thinks that the three processes are equally important, nor do each enterprise choose the same open innovation process or integrate the three core processes at the same level, but choose one. The main process is to integrate the elements of the other two processes [19]. The acquisition, absorption and exploitation of knowledge flow across the organizational boundaries is the key to the creation of organizational innovation, especially inbound and outbound knowledge flow [20].

Moreover, different types of enterprises pay attention to the knowledge process in open innovation on different stages. Large enterprises pay more attention to the R\&D stage of open innovation, while small and medium-sized enterprises (SMEs) pay more attention to the commercialization stage, because many SMEs have advantages in technological innovation, while their production equipment, marketing channels and global innovation market access are scarce. SMEs can only benefit from innovation only if they succeed in the commercialization of innovation results [21]. Therefore, the main obstacle for SMEs to adopt open innovation is their ability of quickly absorbing and assimilating the knowledge obtained from outside to commercialize the innovation results and reduce the $\mathrm{R} \& \mathrm{D}$ cost. Therefore, the key to open innovation of Chinese agricultural enterprises is to establish some internal mechanisms for acquiring, absorbing and exploiting external knowledge.

\section{B. The Adoption of Open Innovation in Chinese Agricultural Enterprises}

The secondary innovation, industry-universityresearch cooperation, innovation incubator and independent innovation are widely adopted by agricultural enterprises in China. Although these enterprises have established certain cooperation with the external organizations, their process of innovation has a certain openness, but there are some problems, such as weak main body position, low innovation level and poor original innovation which results from low openness of the existing technological innovation mode of those enterprises [22]. In particular, independent innovation has been rarely successful in agricultural enterprises because of its long $R \& D$ cycle, high risk, insecure income and insufficient incentives [23].

At the same time, the technological innovation activities of agricultural enterprises have been restricted by many bottlenecks [6], including the difficulty of obtaining the necessary scientific research resources, the lack of R \& D input and talent, the lack of sufficient innovation elements for scientific and technological innovation activities, and the failure to truly achieve "seamless cooperative innovation" in the industry-university-research cooperation, and to play a leading role in the industry-university-research cooperation. Many policy support is insufficient and policy implementation is difficult, while agricultural enterprises are not aware of the role of agricultural science and technology innovation and lack of attention.

Because of the inherent weakness of agricultural enterprises innovation, their operations are highly dependent on the external environment and economic organizations. The open innovation model through assimilation and purchase of domestic technology can promote the increase of scientific and technological innovation output of agricultural enterprises [24], and can also establish connection with open innovation by the infiltration, integration and reorganization of different industries, thus deepening and expanding the open innovation of agricultural enterprises. Furthermore, it helps to form an industrial development mode with highly integrated and dynamic competitive advantages [25]. Therefore, Chinese agricultural enterprises (especially leading enterprises) have a strong desire to adopt open innovation [3]

\section{ENTREPRENEURIAL SOCIAL CAPITAL AND AGRICULTURAL ENTERPRISES INNOVATION}

\section{A. The Types of Entrepreneurial Social Capital}

The social capital of entrepreneurs is embedded in their social relations. Social relations are similar to the common and objective social contact, such as relatives, colleagues and friends, and the actors are involved in social interaction, and they are familiar with each other after exchange and interaction and are willing to contact with each other for a long time [26]. Entrepreneurs' social capital is the social relation owned by entrepreneurs, from which the sum of resources can be obtained. The social capital of entrepreneurs can be divided into institutional, commercial and technical social capital [27]. Institutional social capital is a network of relations between entrepreneurs and government organs, competent departments and financial institutions, which can help enterprises gain reputation. Commercial social capital is a network of entrepreneurs, suppliers, customers and competitors, which can help enterprises obtain favorable information. Technical social capital is a network of entrepreneurs, experts and technicians of universities, scientific research institutions and other enterprises, which can help enterprises acquire new knowledge and market demand.

\section{B. The Impact of Entrepreneurs' Social Capital on Innovation of Agricultural Enterprises}

Social capital can acquire external innovation resources and effectively promote radical innovation. From the perspective of strategic management, social capital can promote the effective transfer of knowledge [28], and can improve the radical innovation ability of enterprises [29]. Entrepreneurs, as the key node of enterprise and social network, can help enterprises to catch up with the technological innovation of enterprises and promote the acquisition, absorption and exploitation of innovative knowledge if they can draw social capital from the social network [30]. Through their own social relations, entrepreneurs can establish cooperative relations with scientific research institutions and universities to obtain innovative resources for enterprises [23], such as capital, technology and talent, to achieve radical innovation. Also, entrepreneurs can produce indirect effects on radical innovation through their failure learning [12].

Entrepreneurial social capital has a positive impact on corporate innovation performance. Some scholars believe that the entrepreneurial system and technical social capital have a 
significant positive impact on corporate performance, while commercial social capital has no significant impact on corporate performance [31]. Other scholars believe that the role of entrepreneurial social capital is limited to the promotion of corporate performance, and both commercial social capital and technical social capital have a significant positive impact on enterprise performance. Enterprise innovation ability [33], independent innovation ability [32], knowledge integration ability [34] have intermediary effect between entrepreneur social capital and enterprise innovation performance, and the enterprise absorptive capacity is adjusting the relationship between them [35]. Entrepreneurs' social capital is helpful to promote the R \& D investment of enterprises, thus promoting the innovation performance of enterprises [36]. Therefore, the social capital of entrepreneurs plays a vital role in the innovation of Chinese agricultural enterprises.

\section{THE IMPACT MECHANISM OF ENTREPRENEURIAL SOCIAL CAPITAL ON OPEN INNOVATION}

Entrepreneurs' social capital is the resource embedded in the social network by entrepreneurs through their social relations. The most important resource is knowledge. The entrepreneurs can acquire, absorb and exploit these knowledge to improve the enterprise radical innovation ability. The problems of "knowledge market failure" and " knowledge management inefficiency" in the technological innovation process of Chinese agricultural enterprises can be solved by embedding entrepreneurs' social capital in the process of open innovation of enterprises, which improve the capabilities of acquisition, absorption and exploitation of enterprise knowledge, so as to improve the innovation performance of enterprises.

\section{A. The impact of Agricultural Entrepreneurial Social Capital on Knowledge Acquisition Capacity}

The agricultural enterprises that can carry out independent $\mathrm{R} \& \mathrm{D}$ are scarce, and their technological innovation depends mainly on the external environment, which leads to the lack of significant influence on the technological innovation performance by the internal social capital of the enterprises [37]. The agricultural enterprises usually take mainly technological innovation activities depending on external resources. The political relations of private entrepreneurs and the relationship of the guild have a significant negative impact on their R \& D investment intensity [38]. Obviously, the innovative resources acquired by entrepreneurs' social capital have an alternative effect on $\mathrm{R} \& \mathrm{D}$ investment.

The business relationship and political relationship of the entrepreneur will significantly promote the knowledge acquisition of the organization. In the government regulated industries, the positive promoting effect of the relationship network on knowledge acquisition will be significantly weakened [39]. There is a significant positive linear relationship between Entrepreneur Social Capital and enterprise joint innovation ability [40], which can influence enterprise innovation ability by improving knowledge acquisition ability.

Therefore, entrepreneurial social capital helps to enhance the knowledge acquisition ability of enterprises in the process of open innovation of agricultural enterprises.

\section{B. The Impact of Agricultural Entrepreneurs' Social Capital on Knowledge Absorptive Capacity}

Knowledge absorptive capacity is the ability of an enterprise or individual to assimilate new knowledge and apply it to business purposes [41]. Entrepreneurs' social capital can have a positive impact on knowledge absorptive capacity from the perspective of structure, relationship and cognition [42].
There is a positive correlation between manager tie and enterprise innovation performance, and knowledge absorptive capacity plays an intermediary role [43]. Entrepreneurs acquire external knowledge sources through their social relations, and conduct knowledge exchange continuously. This interaction can enhance the knowledge absorption ability of enterprises.

The entrepreneur establishes a trustful relationship with the external staff, encourages the "sender" to actively help the "recipient" understand the knowledge it provides. If the sender believes that the recipient is trustworthy and will fulfill its obligations, it will offer help. The higher the degree of trust is, the more willing the parties are to share and exchange information, which will enhance their knowledge absorptive capacity.

Therefore, entrepreneurial social capital helps to enhance the knowledge absorptive capacity of enterprises in the process of open innovation of agricultural enterprises.

\section{The Impact of Agricultural Entrepreneurial Social Capital on Knowledge Exploitive Capacity}

The capacity of knowledge exploitation is the ability to use the existing knowledge and new knowledge comprehensively. It combines three abilities such as systematization, socialization and cooperative ability. Only by obtaining these three abilities can the enterprise improve the effect of knowledge integration [44]. The technological, commercial and institutional social capital of entrepreneurs have significant influence on the ability of knowledge exploitation, and the degree of influence is decreasing gradually [34]. The entrepreneurs' social capital will help the micro enterprises to obtain the opportunities for industry-university-research cooperation, and to promote the patent output of the enterprises [11].

In the context of open innovation, the innovation activities of the enterprise can not be separated from the external participants, and the external joint members of the enterprise are gradually extended from the linear relationship between enterprises to the network relations between enterprises and competitors, users, suppliers, universities and so on. Then, the enterprise can make use of industry-universityresearch cooperation and produce patents, and take advantage of the trust relationship with entrepreneurs and business partners and customers. In this way, they can authorize the technology patent in a variety of ways to make profits.

Therefore, entrepreneurial social capital helps to enhance the knowledge exploitation ability of enterprises in the process of open innovation of agricultural enterprises.

\section{OPEN INNOVATION MODEL OF AGRICULTURAL ENTERPRISES BASED ON ENTREPRENEURIAL SOCIAL CAPITAL}

\section{A. Open Innovation Process}

From the analysis of the technological innovation mode of agricultural enterprises in China, the core processes of the open innovation in agricultural enterprises are the inbound and outbound process, which is mainly used for the acquisition, absorption of external knowledge and the exploitation of internal knowledge.

\section{B. R\&D Stage}

In the $\mathrm{R} \& \mathrm{D}$ phase, agricultural enterprises use more external partnerships to maintain a high level of internal innovation in the limited field of technology, and tend to establish network relations with public research institutions and colleges and universities, because they worry that core technologies are revealed to competitors by other business partners. 


\section{Commercialization Stage}

In the stage of technology commercialization, agricultural enterprises have joined the small and medium enterprises network, thus obtaining information of technological change, technical assistance, market demand and strategic choice of other enterprises, and also can obtain new market opportunities. Because most of China's agricultural enterprises will choose the "enterprise-farmer" production and operation mode to increase the scale of planting business, thus obtaining excess profits. Although farmers do not have the characteristics of enterprises, they are important extension objects of agricultural enterprises' technical achievements [45]. Therefore, farmers have also become an important part of the innovation network of agricultural enterprises in China.

\section{Model and Propositions}

The introduction of the social capital of agricultural entrepreneurs in the traditional open innovation model (Fig.1) will help to analyze the process of knowledge acquisition, absorption and exploitation in the process of open innovation in agricultural enterprises. Based on the above open innovation model of agricultural enterprises, the following propositions are put forward:

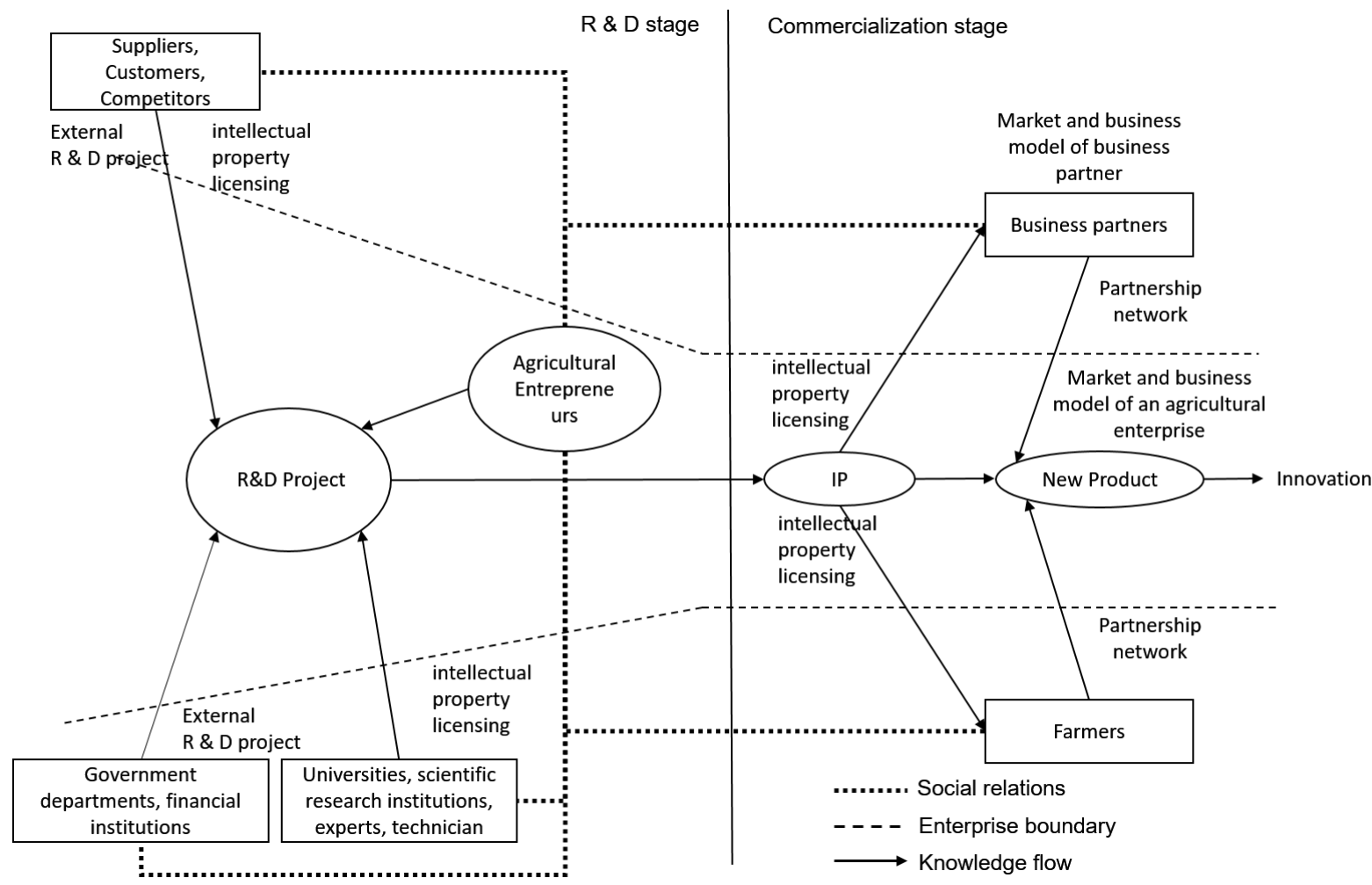

Fig. 1. Open innovation model of agricultural enterprises based on entrepreneurial social capital

1) Agricultural entrepreneurial Social capital is an important channel for knowledge acquisition in open innovation

Agricultural entrepreneurs take advantage of the good private relations with the experts of institutions of higher learning and scientific research institutions, borrow the highclass equipment and talents of their laboratories, open the cooperation of R \& D projects, realize technology sharing, and obtain innovative agricultural technological achievements.

The new projects and new technologies in the laboratories of institutions of higher learning and scientific research institutions are introduced into agricultural enterprises through the way of intellectual property rights, which can be used for internal $\mathrm{R} \& \mathrm{D}$ projects to enable agricultural enterprises to obtain new products and new technologies.

At the same time, agricultural entrepreneurs also make use of good personal relationship with farmers to get individual technological innovation achievements for the secondary innovation of enterprises.

2) Agricultural entrepreneurial social capital is the catalyst for knowledge absorption in open innovation of enterprises
After the agricultural entrepreneur starts the R \& D project with the universities and scientific research institutions, the agricultural entrepreneur has become the principal person in charge of the $\mathrm{R} \& \mathrm{D}$ project, so they can actively communicate and learn from experts and scientific researchers who will help the enterprise to solve the problems encountered in the technological innovation.

With the deepening of understanding and the increasing degree of mutual trust, the degree of knowledge sharing has been improved, and the R \& D personnel in the enterprise have set up a "problem oriented" learning mechanism to speed up the acceptance process of new knowledge in scientific research institutions and improve the R \& D capability of enterprises.

At the same time, entrepreneurs can acquire new knowledge in communication with experts and researchers, then absorb and assimilate them to make new ideas. Entrepreneurs use their social relations with internal R \& D personnel, encourage R \& D personnel to carry out innovation competitions, thus accelerating the research and development of internal projects, as well as developing new products and technologies. 


\section{innovation}

After the development of innovative agricultural technology achievements, entrepreneurs take advantage of good cooperative relationship with business partners to promote agricultural products or agricultural technological achievements to domestic or international markets through agricultural products trade and intellectual property trading, so as to obtain the profits of product sales or intellectual property rights. At the same time, agricultural entrepreneurs make use of the trust relationship with local farmers because of the geographical proximity, extend the new technology to those farmers through the way of intellectual property rights postpaid, and encourage them to test and try these new technologies actively.

Through the diffusion of new technologies such as entrepreneurs' promotion of agricultural technology achievements and demonstration planting of farmers, a large number of market opportunities have been created for the commercialization of new agricultural technologies.

\section{CONCLUSIONS}

The adoption of open innovation by enterprises does not depend on the characteristics of the enterprise, but depends on the internal and external environment of the enterprise and the will of the entrepreneurs. At present, although there are many deficiencies in the technological innovation model adopted by Chinese agricultural enterprises and many restrictions on the external innovation environment, it has already had a certain degree of openness, especially some agricultural leading enterprises have strong willingness to adopt open innovation.

Because of the constraints of the external innovation environment of Chinese agricultural enterprises and the weak quality of internal innovation ability, it is difficult for agricultural enterprises with high dependence on external resources to achieve breakthrough innovation. Open innovation can realize the acquisition and absorption of enterprise external knowledge, integrate with the internal knowledge of enterprises and realize commercial utilization, and break the organization boundaries of the distribution of agricultural enterprises innovative knowledge.

As the breakers of the innovative knowledge boundary, the agricultural entrepreneurs take advantage of their social relations to establish the knowledge flow network among all kinds of knowledge sources inside and outside the enterprise, thus enhancing the knowledge acquisition, absorption and exploitation ability of enterprises, accelerating the flow of knowledge in the process of enterprise innovation, and finally raising the performance of enterprise innovation.

Finally, on the basis of the traditional open innovation model, this paper constructs an open innovation model and related propositions of the agricultural enterprise based on the entrepreneur's social capital. Because the related proposition of the model relies mainly on theoretical derivation, it lacks empirical evidence which can be used as a future research direction

\section{ACKNOWLEDGMENT}

The paper is supported by the National Natural Science Foundation of China (No.71362014), China Postdoctoral Science Foundation Funded Project (No. 2015M570494), and Natural Science Foundation of Yunnan (No.2014FB146), Social Science Foundation of Yunnan (No. YB2017083).
11] Q. Wang, Y. Feng, and Z.G .Ma, "Research on international competitiveness of agricultural products and agricultural enterprises in China," Inquiry into Economic Issues,pp.52-59, April 2017.

[2] H.H. Huan, "Promoting Open Innovation to Enhance the Innovation Capacity of Agricultural Science and Technology," Management of Agricultural Science and Technology,pp.19-22,Octorber 2015.

[3] H.Y. Cui, and J.J. Shi, "Research on the relationship between open innovation, government support and agricultural leading enterprises' performance," Issues in Agricultural Economy,pp.84-91, September 2013.

[4] K.X. Ji, "Research on the mode of Agricultural Technology Innovation: a domestic literature review," Journal of Agricultural Management Institute of Ministry of Agriculture, pp.20-25, December 2015.

[5] J. Toth, and I. Ferto, "Innovation in the Hungarian food economy," AGRICULTURAL ECONOMICS-ZEMEDELSKA EKONOMIKA, pp. 43-51, 2017.

[6] W.D. Xiao, "Bottleneck factors and driving mechanism of agricultural science and technology innovation in agriculture related enterprises," Theory Journal, pp.69-75, January 2016.

[7] J. Dong, "Agricultural technology diffusion and constraint mechanism from the perspective of agricultural industry characteristics and rural social characteristics -Reflections on Mansfield's technology diffusion theory," Science \& Technology Progress and Policy, pp.65-70, May 2012.

[8] X.Q. Liu, J. Cai, and C.W. Liu, "The Characteristics of Agricultura Industry and Its Influence on Structural Dimension Features of Agricultural Enterprise," JOURNAL OF SOUTH CHINA AGRICULTURAL UNIVERSITY(SOCIAL SCIENCE EDITION),pp.11-20, 2012.

[9] X.Q. Liu, D. Ma, and J. Luo, "Origin and efficiency of agricultura enterprises: Based on the characteristics of rural social capital," JOURNAL OF SOUTH CHINA AGRICULTURAL UNIVERSITY( SOCIAL SCIENCE EDITION) ,pp.72-79, 2010.

[10] S.R. Zhang, and S.Y. Wu, "Particularity and realization path of social responsibility of agricultural enterprises," Jiangsu Agricultural Sciences, pp.418-420,2013.

[11] Z.G. Zhang, Y.J. Li, and S.F. Yuan, "Study on the Relationship Between Entrepreneurial Social Capital, Industry-UniversityResearch Cooperation and Patent Output: The Moderating Role of Intention to Cooperative Innovation," Science of Science and Management of S.\& T. , pp.54-64, July 2016.

[12] C.W. Zha, W.M. Chen, and C. Peng, "External Social Capital Learning from Failures and Radical Innovation," Forum on Science and Technology in China, pp.109-113+136, February 2015.

[13] C.W. Zha, W.M. Chen, and C.Y. Tang, "High Quality Relationship, Learning from Failure and Innovation Performance of Enterprises,' Management Review, pp.175-184, February 2016.

[14] Oparaocha, G.O., "Towards building internal social network architecture that drives innovation: a social exchange theory perspective," JOURNAL OF KNOWLEDGE MANAGEMENT, pp.534-556, 2016

[15] H.W. Chesbrough, "The era of open innovation," MIT SLOAN MANAGEMENT REVIEW, pp.35-41, 2003.

[16] H. Chesbrough, "Open Innovation: A New Paradigm for Understanding Industrial Innovation," ,2006

[17] H. Chesbrough, and M. Bogers, "Explicating Open Innovation: Clarifying an Emerging Paradigm for Understanding Innovation,' Social Science Electronic Publishing, 2014.

[18] M.M. Keupp,. and O. Gassmann, "Determinants and archetype users of open innovation," R\&D Management, pp.331-341, 2009.

[19] O. Gassmann, and E. Enkel, "Towards a Theory of Open Innovation Three Core Process Archetypes," 2004.

[20] H. Chesbrough, "The Future of Open Innovation: The Future of Open Innovation Is More Extensive, More Collaborative, and More Engaged with a Wider Variety of Participants," ResearchTechnology Management, 2017

[21] Lee, S., et al., "Open innovation in SMEs-An intermediated network model," Research Policy, pp.290-300, 2010.

[22] W.J. Li, and Y.J. Li, "The Mode, Risk, Problems and Countermeasures of Agricultural Enterprise' s Scientific and Technological Innovation," Science and Technology Management Research, pp.7-12, 2015.

[23] T.S. Liu, "Scientific and technological innovation model and Development Countermeasures for agriculture related enterprises," Modern Management Science, pp.48-50, 2014. 
[24] L.H. Xie, and S.P. Mao, "The current situation, influencing factors and Countermeasures of technological innovation in China's agriculture related enterprises," Issues in Agricultural Economy, pp.87-96,2016.

[25] Y. Li, and J. Yang, "Industry Chain Integration Model about Agriculture Case Studies from the Perspective of Industry Convergence," China Soft Science, pp.27-36,2017.

[26] B. Guo, "Hierarchical Control of Agricultural Enterprises' Development: Example of Henan Province," Reform, pp.70-76, October 2012

[27] H. Li, and C. Wang, "The Influence Mechanism of Entrepreneurs' Social Capital on Enterprises' Dynamic Capability-Based on the Mediation Effect of Independent Innovation Level," Economic Survey, pp.107-112, March 2016.

[28] Huggins, R., Forms of Network Resource: Knowledge Access and the Role of Inter-Firm Networks. INTERNATIONAL JOURNAL OF MANAGEMENT REVIEWS, 2010. 12(3): p. 335-352.

[29] Y.G. Wang, R. Li, and Q.Y. Tao, "Intelligent Capital Attributes and Environmental Turbulence on Dual Innovation Capabilities," Research on Economics and Management, pp.86-93, March 2016.

[30] Y.C. Huang, L.Z. Wang, and J.H. Zheng, "Human capital, social capital and technological catching up of entrepreneurs in emerging industries: a case study of Kunshan, Jiangsu," Jiangsu Social Sciences, pp.70-78, 2014

[31] J.Z. Ao, J.Y. Wan, and L. Huang, "The Impact of Social Capital on Agriculture Enterprises Performance," Soft Science, pp.117-121, September 2013.

[32] H.Li, and X.M.Zhang, "Social capital, independent innovation capability and corporate performance of small and medium sized Entrepreneurs: An Empirical Study of SMEs in Shanxi," Forum on Science and Technology in China, pp.135-142, June 2013.

[33] Y. Yang, "Entrepreneurial social capital, enterprise innovation capability and performance," Social Sciences In Heilongjiang, pp.49-52, 2015.

[34] J.J. Wu, and Y. Dai, "Research on the relationship between entrepreneurial social capital, knowledge integration capability and technological innovation performance," Science \& Technology Progress and Policy, pp.84-88, June 2013.

[35] C. Xu, and R.Y. Chi, "Entrepreneurs' Social Capital, Corporate Absorptive Capacity and Corporate Performance," Science \& Technology Progress and Policy, pp.82-88, May 2016
[36] S.H. Li, and L. Gao, "Social Capital, R\&D Investment and Enterprise Performance Based on the Perspective of Instrumental Utility Heterogeneity," SCIENCE OF SCIENCE AND MANAGEMENT OF S. \& T., pp.105-115, October 2014.

[37] B. Zhou, Y.J. Li, and L. Sun, "The impact of corporate social capita on technological innovation performance -- An Empirical Study of agricultural enterprises," Science and Technology Management Research, pp.136-139, May 2009.

[38] S.Y. Chen, R.T. Jing, and K.R. Liao, "How do social capital, corporate governance effect on private enterprise's R \& D investment intensity," Studies in Science of Science, pp.916-922, June 2012.

[39] C.D. You, J.Q. Zhang, and Y.L. Zhang, "Entrepreneurial Network and Organizational Knowledge Acquisition:the Moderating Effect of Industrial Regulation," JOURNAL OF INTELLIGENCE, pp.195-201, June 2016.

[40] T. Wang, and Z.J. Chen, "Impact of Entrepreneur's Social Capita on Technological Innovation Capability," Journal of Xinjiang University (Philosophy,Humanities \& Social Science), pp.11-18, December 2016.

[41] Cohen, W.M. and D.A. Levinthal, "Absorptive Capacity: A New Perspective on Learning and Innovation," Administrative Science Quarterly, pp.128-152, 1990.

[42] J. Chen, Z.J. Jiang, and Y.F. Chen, "The Influencing Factors of Absorptive Capacity under the Paradigm of Open Innovation,' Journal of Zhejiang University(Humanities and Social Sciences) pp.71-82, September 2011.

[43] T. Chen, and Y.H. Sheng, "Managerial Ties, Knowledge Absorption and New Venture Innovation Performance," Nanjing Journal of Social Sciences, pp.42-47, 2012.

[44] De Boer, M., F.A.J. Van Den Bosch and H.W. Volberda, "Managing Organizational Knowledge Integration in the Emerging Multimedia Complex," Journal of Management Studies, pp.379-398, 1999.

[45] B. Guo, "The Innovation of Agricultural Enterprise 'Company+Farmers' Production Business Model," Journal of Northwest A\&F University(Social Science Edition), pp.76-82, November 2014. 